\title{
Seasonal Model and Its Application in Short-term Forecasting
}

\author{
Xiangrong Jiang, Liping $\mathrm{Xu}^{*}$ and Yingying Cui \\ Institute of Science and Technology for Development of Shandong, Qilu University of Technology(Shandong Academy of \\ Sciences), Jinan, China \\ ${ }^{*}$ Corresponding author
}

\begin{abstract}
With economic activity changes periodically as the seasons vary, the time series of macroeconomic data is usually seasonal. This paper is different from the traditional way of proceeding seasonal adjustment before analyzing the macroeconomic time series. Instead, we propose a seasonal prediction model based on the stable seasonal variation pattern of time series to conduct short-term prediction. The basic principle of the model is to first establish the conditional distribution of the total accumulation based on the known observed values and to estimate the seasonal parameters on historical data using the maximum likelihood method. And then conduct prediction with the observations observed and the estimated parameters for the seasonal pattern. The model shows high prediction efficiency for the time series with stable seasonality through the empirical analysis.
\end{abstract}

Keywords—seasonality; time series; forecasting; ARIMA

\section{INTRODUCTION}

In 1905, Yule et al. proposed that the change of economic time series generally involves four components such as trend (T), seasonality (S), cycle (C) and irregular fluctuations (I). Among them, seasonality is a kind of regular fluctuation that is repeated year after year due to climate change, fixed holidays and other factors. The seasonal fluctuation of economic time series is very significant and is often considered to be easy to obscure and confuse other objective changes in economic development. Therefore, it is common practice to carry out seasonal adjustments to eliminate seasonality when conducting analysis and forecasting on economic growth and macroeconomic situation. Seasonal adjustment is essentially to remove the seasonal component of a time series that exhibits a seasonal pattern using mathematical models.

Research on seasonal adjustment method can be traced back to the 17th century internationally. In 1919 the American economist Persons firstly proposed the model to decompose time series into T, S, C and I components. And then the thought of seasonal adjustment began to gradually establish ${ }^{[1]}$. The large-scale application of seasonal adjustment was after the advent of computer technology. Shiskin and Eisenpress (1957) [2] took the lead in using the computer to make seasonal adjustments. By the 1980s, X-11 method widely used in the worldwide was a non-parametric seasonal adjustment method based on the moving average method. It filtered the time series by multiple moving averages and removed the seasonal factors while keeping the trend factors and irregular factor. Since the 1980 s, as time series theory analysis technology ${ }^{[3]}$, computer network technology has been continuously improved, the model-based season adjustment method appears and continues to improve, which extracts various components (SEATS) from the original sequence trends by modeling of trends, seasons, cycles and irregular components according to the signal extraction theory. Tthe TRAMO / SEATS system developed by the Spanish Central Bank is based on this principle. Later study on the season adjustment method focuses on improvement of the $\mathrm{X}-11$ and SEATS methods ${ }^{[4]}$.

In the application and practice of seasonal adjustment methods, many countries including the United States, Canada, the United Kingdom, and Australia have released both seasonally adjusted data and unadjusted data on the statistical website. The data covers GDP, CPI, employment, industry, and construction industry, external trade and other fields. At the same time, central banks also regularly release important financial indicators that both seasonally adjusted data and unadjusted. In addition, developed countries in the world are constantly developing and improving seasonal adjustment software and publishing a variety of books on seasonal adjustment models and software applications to guide the seasonal adjustment of important economic data.

The seasonality of China's economic time series is more complex than that of the West, because it includes a large number of moving holidays, traditional lunar holidays, and other influencing factors. However, research on seasonality of time series in China started relatively late, and most of the studies are empirical analysis of China's macroeconomic indicators based on the theory and methods for the West. There are few original innovations on seasonal adjustment models for China. In practice, National Bureau of Statistics of China released the seasonally-adjusted data for a few indicators only after April 2011. It has not yet been able to release seasonally adjusted data for most key economic indicators, which has a certain influence on the scientificity and accuracy of the quantitative analysis research carried out by domestic scholars in macroeconomic analysis and prediction.

Our study finds that in the case of a relatively stable seasonal sequence, we can use this stable seasonality to establish a new total forecasting model (We call it the Accumulation Predicting Model (APM model), which greatly improves the prediction accuracy. The main principle of the model is to establish the functional relationship between the partial accumulation and the end-of-season totals using historical data, and then apply the function to forecast the coming end-of-season total using the partial accumulation by 
using the already known partial accumulation. This method of using the partial accumulation to predict the total amount can be found in some literatures ((Chen \& Fomby, 1999; de Alba, 1988; Guerrero \& Elizondo, 1997; Lenk, 1992; Oliver, 1987) and when the time series shows a stable seasonality, this method has a better predictive effect than the traditional forecasting method.

\section{Stable Seasonal Time Series Forecasting MODELING}

\section{A. Basic Notations}

Before our research, we need to define and standardize some of the concepts.

- Let series $X_{t}=\left\{\ldots, x_{t 1}, x_{t 2}, \ldots, x_{t d}\right\}$ denote a seasonal time series where $t=1,2 \ldots, n$ are season (year) indices, $n$ is the maximum number of seasons of the time series, and $d$ is the length of each season.

- It is assumed that $Y_{t}=\sum_{j-1}^{d} x_{t j}$ is the accumulation of the total season and $\mathbf{Y}_{\mathbf{n}}=\left\{Y_{1}, Y_{2}, \ldots, Y_{n}\right\}$ is the series of total accumulation for $n$ seasons.

- It is assumed that $Y_{t}^{k}=\sum_{j=1}^{k} x_{t j}$ is partial accumulation of the first $k t h$ observations of the $t$ th season and $Y_{t}^{d}=Y_{t} ; \mathbf{Y}_{\mathbf{t}}=\left\{Y_{t}^{1}, Y_{t}^{2}, \ldots, Y_{t}^{n}\right\}$ is the series of partial accumulation for the $t$ th season.

- The seasonal pattern within year $t$ given $Y_{t}$ is described by parameter $\theta_{t}^{k}$ and $0 \leq \theta_{t}^{k} \leq 1$; $\theta_{t}^{k}$ and $Y_{t}$ are independent.

\section{B. Seasonality Based Forecasting Model}

Discussions on the stable seasonality of time series have been mentioned in many literatures. For example, stable seasonality can be expressed as: the relationship between the partial accumulation and the total accumulation at the end of the season for each season is the same or similar (Marshall and Oliver 1979; Chen and Formby 1999; de Alba and Mendoza 2001; Mendoza and de Alba 2006), although the total accumulation will change. In this paper, stable seasonality means parameter $\theta_{t}^{k}$ won't evolve with time, which is $\theta_{1}^{k} \approx$ $\theta_{2}^{k} \approx \cdots \approx \theta_{n}^{k} \cong \theta^{k}$.

Consider function $M$ :

$$
P\left(Y_{t}^{k} \mid Y_{t}\right) \sim M\left(Y_{t}, \theta^{k}\right)
$$

With assumptions:

- the probability that the sum of first kth observations is $Y_{t}^{k}$ is $\theta^{\mathrm{k}}$ on condition that the total accumulation of the season is $Y_{t}$;

- the observations $X_{t}^{1}, X_{t}^{2}, \ldots X_{t}^{d}$ in each season are independent;

- $\quad \theta^{k}$ and $Y_{t}$ are independent.

Based on the assumptions above, we further assume that for $0 \leq k \leq d, M$ is a conditional Binomial distribution as:

$$
P\left(Y_{t}^{k} \mid Y_{t}, \theta^{k}\right) \sim \operatorname{Binomial}\left(Y_{t}, \theta^{k}\right)
$$

So according to the properties of mean of the binomial distribution, we can get:

$$
\mathrm{E}\left(Y_{t}^{k}\right)=Y_{t} \times \theta^{k} \Rightarrow Y_{t}=\mathrm{E}\left(Y_{t}^{k}\right) / \theta^{k}
$$

Our task is to forecast the end-of-season total of the $n+$ 1 th season $Y_{\mathrm{n}+1}$ given the observations series of the first $n$th seasons and the $k$ th observations within the $n+1$ th season. From equation (3) we know that

$$
\hat{Y}_{n+1}=Y_{n+1}^{k} / \hat{\theta}^{k}
$$

So we need to estimate parameter $\theta^{\mathrm{k}}$. For $\mathrm{t}=1,2, \ldots, \mathrm{n}$, the joint conditional probability density function can be expressed as:

$$
\begin{aligned}
& P\left(Y_{1}^{k}, Y_{2}^{k}, \ldots, Y_{n}^{k} \mid Y_{1}, Y_{2}, \ldots, Y_{n}, \theta^{k}\right) \\
= & \prod_{i=1}^{n}\left(C_{Y_{i}}^{Y_{i}^{k}} \times\left(\theta^{k}\right)^{Y_{i}^{k}}\left(1-\theta^{k}\right)^{Y_{i}-Y_{i}^{k}}\right)
\end{aligned}
$$

From equation (5 ) we can get the log likelihood function of $\theta^{k}$ as:

$$
\begin{aligned}
& \log -\operatorname{likelihood}\left(\theta^{k} \mid Y_{1}^{k}, \ldots, Y_{n}^{k}, Y_{1}, \ldots, Y_{n}\right) \\
& \propto \sum_{i=1}^{n} Y_{i}^{k} * \log \theta^{k}+\sum_{i=1}^{n}\left(Y_{i}-Y_{i}^{k}\right) \log \left(1-\theta^{k}\right)
\end{aligned}
$$

The function expressed in equation (6) can be optimized with the restriction $0 \leq \theta_{t}^{1} \leq 1$ and $\theta_{t}^{d}=1$,

$$
\hat{\theta}^{k}=\frac{\sum_{j=1}^{k}\left(\sum_{i=1}^{n} X_{i}^{j}\right)}{\sum_{i=1}^{n} Y_{i}}
$$

We can use equation (4) together with the $\hat{\theta}^{k}$ from equation (7) to do forecasting.

\section{ApPlication Of THE MODEL}

We will apply the forecasting model suggested in the previous section to conduct short-term forecasting using some key macroeconomic indicators in this part. The data is quarterly and is from 2007 to 2008, including GDP, Primary industry output value, Second industry output value and Tertiary industry output value. From Figure I we can see that all the data we use in this section have stable seasonality. And it is appropriate to apply our model to make predictions. 


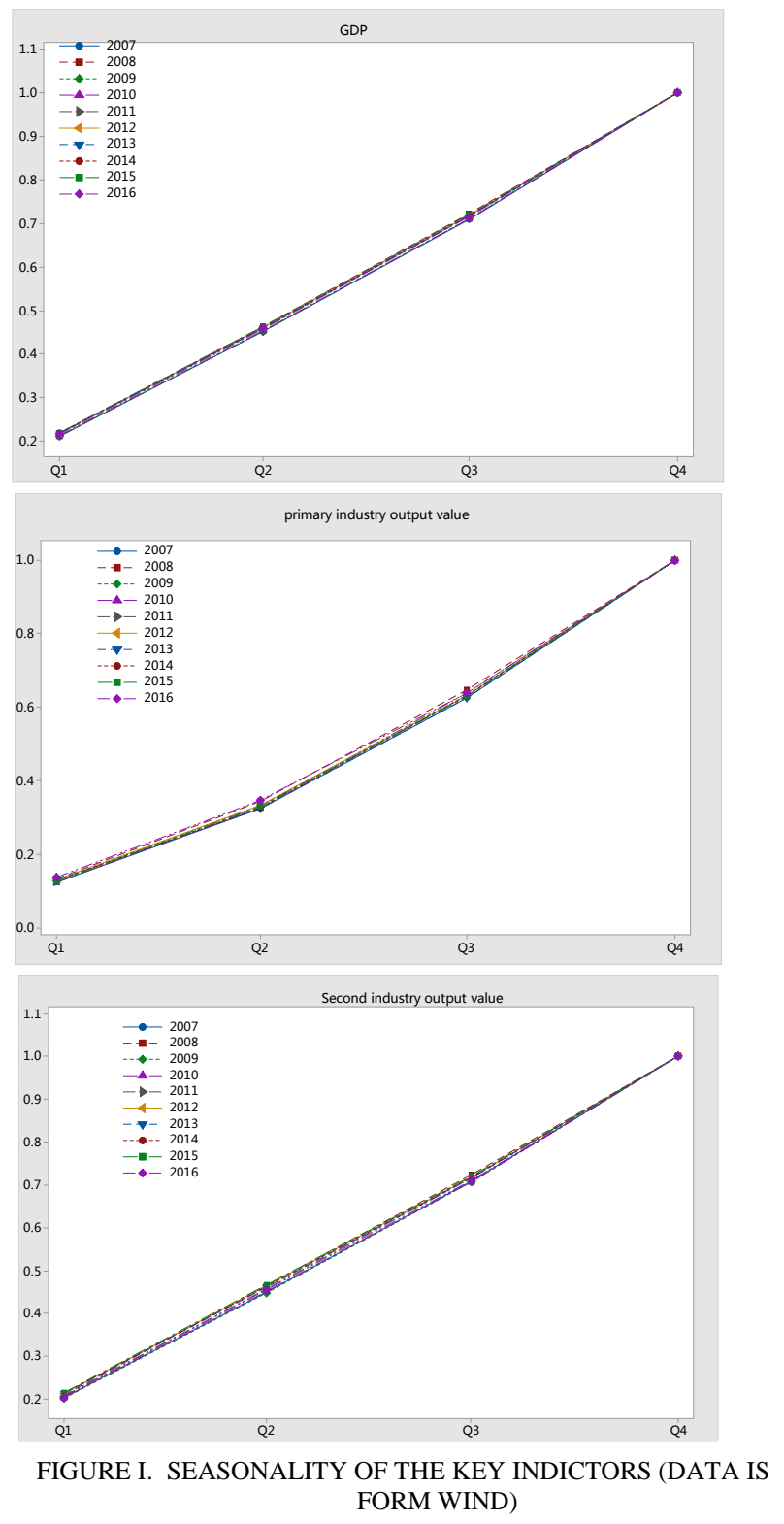

So we conduct rolling prediction with data every 5 years with both our model and ARIMA. The result is as Table I.

TABLE I. FORECASTING RESULT INDICTORS

\begin{tabular}{|c|c|c|c|c|c|}
\hline & Model & RMSE & MAE & MAPE & TIC \\
\hline \multirow[b]{2}{*}{ GDP } & Our model & 2736.77 & 2570.35 & 0.4028 & 0.0021 \\
\hline & $\begin{array}{c}\text { ARIMA } \\
(3,1,0)\end{array}$ & 2476.12 & 2087.62 & 0.3073 & 0.0019 \\
\hline \multirow[b]{2}{*}{$\begin{array}{l}\text { Primary } \\
\text { industry }\end{array}$} & Our model & 546.04 & 422.57 & 0.7316 & 0.0047 \\
\hline & $\begin{array}{c}\text { ARIMA } \\
(3,1,0)\end{array}$ & 680.98 & 573.08 & 1.0331 & 0.0059 \\
\hline \multirow[b]{2}{*}{$\begin{array}{l}\text { Second } \\
\text { industry }\end{array}$} & Our model & 2220.17 & 2016.49 & 0.7313 & 0.0041 \\
\hline & $\begin{array}{c}\text { ARIMA } \\
(3,1,0)\end{array}$ & 2437.40 & 1883.82 & 0.6779 & 0.0045 \\
\hline \multirow[b]{2}{*}{$\begin{array}{l}\text { Tertiary } \\
\text { industry }\end{array}$} & Our model & 598.53 & 588.01 & 0.1934 & 0.0009 \\
\hline & $\begin{array}{c}\text { ARIMA } \\
(3,1,0)\end{array}$ & 2602.23 & 2431.34 & 0.7525 & 0.0041 \\
\hline
\end{tabular}

\section{CONCLUSION}

The seasonal forecast model constructed in this paper can make simple, convenient and efficient forecasting by modeling the stable seasonality of the time series. From the empirical analysis, we can see that using the seasonal forecasting model to perform five rolling forecasts, the MAPE is controlled within $1 \%$, the TIC is far less than 1 , the prediction accuracy is relatively high, and the prediction efficiency of the model is good. However, this model only speaks with data and fails to theoretically explain the principle. It also fails to provide interval prediction from a more rigorous point of view. And when the economic phenomenon or structure changes, the seasonal characteristics will change. In the seasonal modeling and parameter estimation should take a more rigorous approach to reflect the seasonal changes. In future studies, we will further consider these factors and further enhance the scope and rigor of the model.

\section{ACKNOWLEDGEMENTS}

This paper is supported by Think-Tank Innovation Project from Shandong Academy of Sciences.

\section{REFERENCES}

[1] SHISKIN J, H EISENPRESS. Seasonal Adjustments by Electronic Computer Methods [J]. Journal of the American Statistical Association, 1957( 52) : 415 - 449.

[2] D.B. Hertz and K. H. Schaffir (1960), "A Forecasting Method for Management of Seasonal Style-Goods Inventories," Operations Research, Vol. 8, No. 1, 45-52.

[3] G. R. Murray Jr. and E. A. Silver (1966), "A Bayesian Analysis of the Style Goods Inventory Problem,” Management Science, Vol. 12, No. 11; p. 785-797.

[4] S. H. Chang and D. E. Fyffe (1971), "Estimation of Forecast Errors for Seasonal-Style-Goods Sales,” Management Science; Vol. 18, 89-96.

[5] M. Green and P. J. Harrison (1973), "Fashion Forecasting for a Mail Order Company Using a Bayesian Approach,” Operational Research Quarterly, Vol. 24, No. 2, 193-205.

[6] M. Oliver (1987), "Bayesian Forecasting with Stable Seasonal Patterns," Journal of Business \& Economic Statistics, 5, 77-86.

[7] V. M. Guerrero and J. A. Elizondo (1997), "Forecasting a Cumulative Variable Using Its Partially Accumulated Data,” Management Science, Vol. 43, No 6, 879-889.

[8] Rong Chen, Thomas B. Fomby. Forecasting With Stable Seasonal Pattern Models With an Application to Hawaiian Tourism Data[J]. Journal of Business \& Economic Statistics, 1999, 17(4):497-504.

[9] M. Mendoza and E. de Alba (2006), "Forecasting an Accumulated Series Based on Partial Accumulation II : A New Bayesian Method for Short Series With Seasonal Patterns," International J. of Forecasting, Vol. 22, no. 4, 781-798.

[10] E. de Alba and M. Mendoza (2001), "Forecasting an Accumulated Series Based on Partial Accumulation: A Bayesian Method for Short Series with Seasonal Patterns,” Journal of Business \& Economic Statistics, and Vol. 19, No 1, 95-102.

[11] Burman, P. and Shumway, R.H. (1998), "Semiparametric Modeling of Seasonal Time Series”, Journal of Time Series Analysis, 19, 127-145

[12] Marshall, K.T, and Oliver, R.M. (1970), “A constant work model for Student Enrollments and Attendance” Operations Research Journal, 18,193-206.

[13] Marshall , K.T, and Oliver, R.M. (1979), "Estimating Errors in Student Enrollment 